http://dx.doi.org/10.11646/zootaxa.3640.1.5

http://zoobank.org/urn:lsid:zoobank.org:pub:EF0B984A-FE66-47EB-90CF-EEC7C6B5554C

\title{
Taxonomic revision of the genus Brounopsis Blair (Coleoptera: Cerambycidae: Cerambycinae) with description of four new species
}

\author{
QIAO WANG ${ }^{1,3} \&$ WEN LU ${ }^{2}$ \\ ${ }^{1}$ Institute of Natural Resources, Massey University, Private Bag 11222, Palmerston North, New Zealand \\ ${ }^{2}$ College of Agriculture, Guangxi University, Guangxi 530005, China \\ ${ }^{3}$ Corresponding author. E-mail: Q.Wang@ massey.ac.nz
}

\begin{abstract}
The longicorn beetle genus Brounopsis Blair, 1937, is revised. A diagnosis of Brounopsis and a key to all five species of the genus are given. One previously known species, B. hudsoni Blair, 1937, is redescribed, and four species described as new: B. concolora sp. nov., B. nigrifacta $\mathbf{s p . ~ n o v . , ~ B . ~ d e i t z i ~ s p . ~ n o v . ~ a n d ~ B . ~ g o u r l a y i ~ s p . ~ n o v . ~ D o r s a l ~ v i e w s ~ o f ~ e a c h ~ s p e c i e s ~}$ are provided as photographs. The genus occurs exclusively in the South Island of New Zealand and is associated with Cassinia spp. (Asteraceae).
\end{abstract}

Key words: Cerambycidae, Pytheini, Brounopsis, new species

\section{Introduction}

The genus Brounopsis was erected by Blair (1937) based on two specimens from the South Island of New Zealand. Since then, many specimens have been collected but no taxonomic treatment on this genus has been made. Brounopsis is associated with Cassinia R.Br. in Asteraceae.

In this paper, we provide a diagnosis of the monotypic genus Brounopsis in the tribe Pytheini, redescription of the single described species, description of four new species, and an identification key to all five species.

\section{Material and methods}

Specimens were borrowed from the following institutions in New Zealand, abbreviations of which were shown in the text:

CMNZ Canterbury Museum, Christchurch

LUNZ Lincoln University, Canterbury

MONZ Museum of New Zealand, Wellington

NZAC New Zealand Arthropod Collection, Auckland

WMNZ Whangarei Museum, Whangarei

External morphological measurements were made under a Leica M212 stereomicroscope. Dorsal views of each species were photographed using a Canon Power Shot G5 digital camera.

Morphological terminology in this study follows that of Lawrence and Britton (1991), Bense (1995), Wang (1998), Wang and $\mathrm{Lu}(2004)$ and Lu and Wang (2005a \& b).

Area codes for specimen collection localities follow Crosby et al. (1998), and plant names and their taxonomic placement follow Orchard (2004). 


\section{Taxonomy}

\section{Genus Brounopsis Blair}

Brounopsis Blair, 1937: 267.- Leschen et al., 2003: 24.

Type species: B. hudsoni Blair, 1937: 267, by monotypy.

Diagnosis. The genus can be distinguished by a combination of the following characters: head width $<3 \times$ as long as distance between upper lobes of eyes; head and pronotum with dense coarse punctures and long pale or yellowish hairs; antennae not reaching elytral apex; pronotum wider than long, each side rounded or with a rounded tubercle near middle; elytra $>3 \times$ as long as prothorax; elytral disc with dense and round punctures, each bearing a pale or yellowish hair; elytral apex rounded or slightly truncate; femora not clavate; hind femur longer than hind tibia; front coxae globular, projecting above intercoxal process.

\section{Key to the species of Brounopsis Blair}

1. Elytron yellowish to reddish brown without any dark stripe $\ldots \ldots \ldots \ldots \ldots \ldots \ldots \ldots \ldots \ldots \ldots \ldots$. concolora, sp. nov.

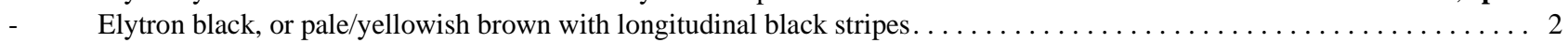

2. Elytron entirely black, or mostly black with a vague longitudinal dark brownish stripe on disc ....... B. nigrifacta, sp. nov. Elytron pale/yellowish brown with two longitudinal black stripes, one on suture and another on the edge between disc and epi-

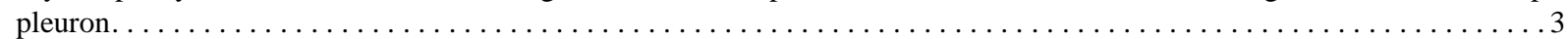

3. Sutural black stripe short, usually shorter than $1 / 2$ of elytral length, and never reaching elytral apex; the black stripe on the edge much longer but usually not reaching elytral apex; legs yellowish brown $\ldots \ldots \ldots \ldots \ldots \ldots \ldots \ldots \ldots$. hudsoni Blair Black stripes on suture and edge reaching elytral apex; legs black or dark reddish brown $\ldots \ldots \ldots \ldots \ldots \ldots$

4. Each side of pronotum with a clearly defined and produced tubercle; most hairs from punctures on elytral disc $<2 \times$ as long as puncture diameter except those on basal and apical areas; hind femur 1.01-1.03 $\times$ as long as hind tibia ... B. deitzi, sp. nov. Each side of pronotum rounded or feebly tuberculate; most hairs from punctures on elytral disc $>2 \times$ as long as puncture diameter; hind femur $1.10-1.20 \times$ as long as hind tibia............ gourlayi, sp. nov.

\section{Brounopsis concolora, sp. nov.}

(Fig. 1)

Material examined. Holotype., , NN: Mt Arthur, 4,100 ft, 24.iii.1971, ex Cassinia vauvilliersii, J. S. Dugdale (NZAC). Paratypes. 3 , $\mathbf{N N}: 1$, same data as holotype (NZAC); 1 \%, same locality as above but 3.ii.1965, G. Kuschel \& A.K. Walker (NZAC); 1 , , Gordons Pyramid, 4,500 ft, 13.i.1918 (NZAC).

Description. Female (Fig. 1)

Body length. 13.5-18.5 mm; body width. 3.4-4.5 mm.

Colour. Antennae, palpi, labrum, clypeus, postclypeus, elytra and legs yellowish to reddish brown; antennal segments 5-7 near apex and segments 8-11 may be darker; mandibles reddish to blackish brown; head and thorax black; a small area along median line and sides (or part of sides) of pronotum and metasternum reddish brown; abdomen yellowish to reddish brown but parts of first 2 visible sternites dark.

Head. Head with dense, coarse, deep and more or less irregular punctures and long golden hairs; head width 2.4-2.5 $\times$ as long as distance between upper lobes of eyes; head width immediately below eyes $4.4-5.2 \times$ as long as genal length. Antennae not reaching middle elytra; scape $1.40-1.46 \times$ as long as segment 3 .

Thorax and abdomen. Prothorax width 1.08-1.22 $\times$ as long as length, sides rounded or slightly produced near middle. Pronotal disc with dense, coarse and more or less irregular punctures, each bearing a long golden hair; disc with 2 slightly raised tubercles before middle and 2 slightly depressed areas behind middle; denser and shorter hairs arising from each side of disc behind middle. Sterna with dense irregular punctures and long golden hairs. Elytra 4.2-4.4 $\times$ as long as prothorax; elytral disc with dense coarse punctures, each bearing a golden hair; most hairs in middle area $>2 \times$ as long as puncture diameter; apex rounded or slightly truncate. Hind femur 1.14-1.16 $\times$ as long as hind tibia; hind tarsal segment $1<$ or as long as segments $2+3$. Abdomen shiny with relatively dense and very fine punctures bearing fine and short golden hairs, and sparse long golden hairs arising in areas along median longitudinal line. 


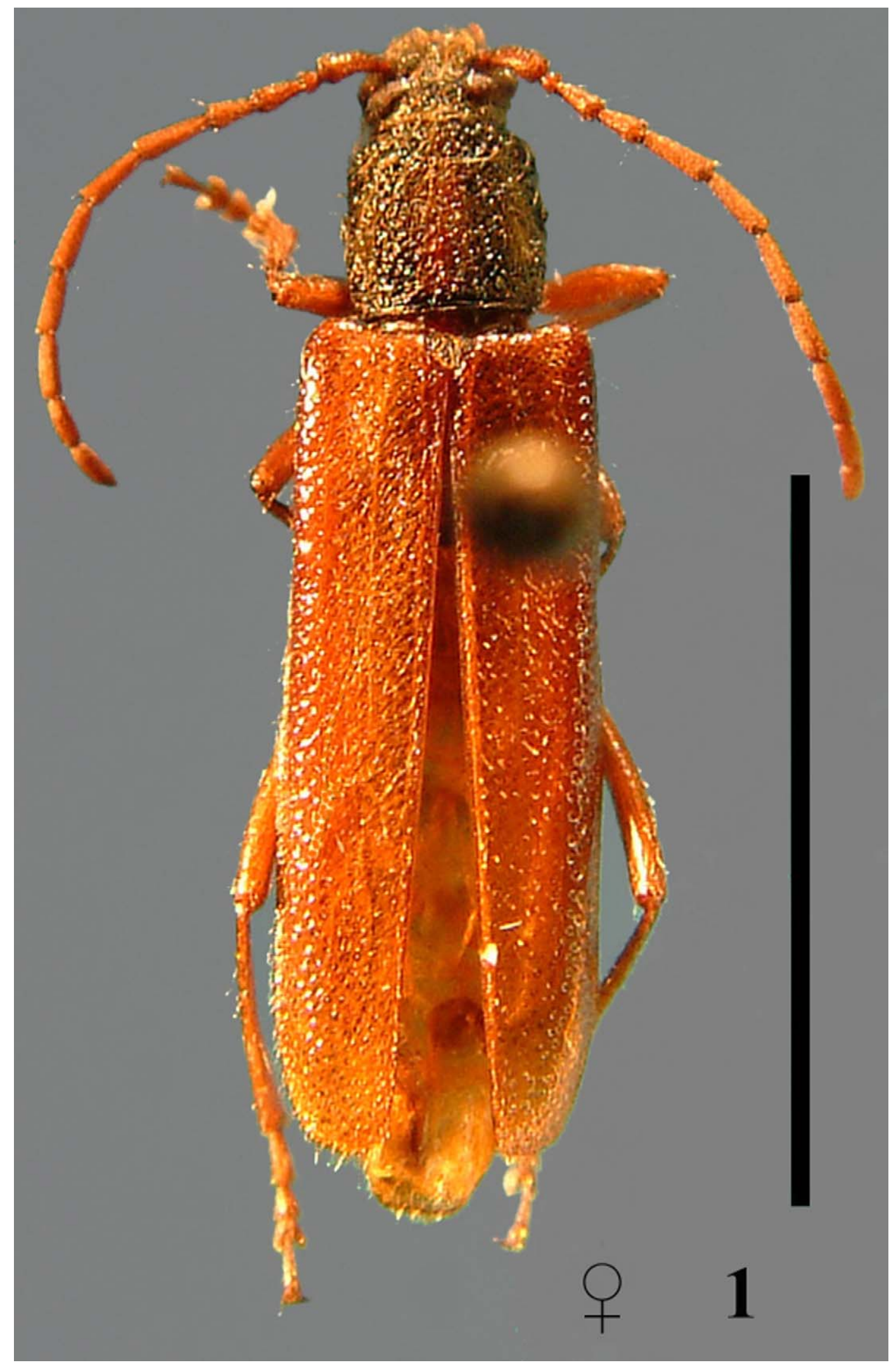

FIGURE 1. Dorsal view of Brounopsis concolora, sp. nov. Scale bar $=10 \mathrm{~mm}$.

Male. Unknown.

Biology. Known host is Cassinia vauvilliersii (Homb. Et Jacq.). Adults emerged in January to March.

Distribution. Nelson of South Island.

Etymology. Named in reference to the uniform reddish colour of the elytra without dark stripes. 
Comments. The new species resembles $B$. hudsoni but differs in having no dark stripes on elytral disc and antennae not reaching middle elytra.

\section{Brounopsis nigrifacta, sp. nov.}

(Figs 2-3)

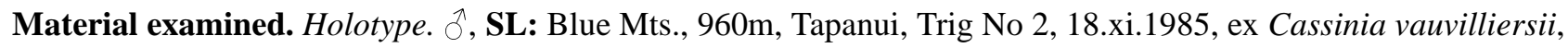
C.A. Muir (LUNZ, the specimen bears a red holotype label).

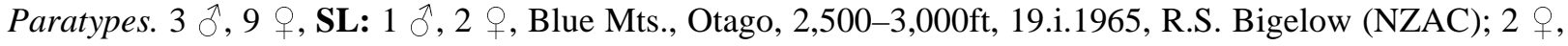
Blue Mts., 1,000m, Tapannui, No 2, 18.xi.1985, reared from Cassinia vauvilliersii, J.S. Dugdale (NZAC); 1 ${ }^{\lambda}$, same data as above but 970 m, 21.xi.1985 (NZAC); 3 ㅇ, Blue Mts., Tamitimu Range, 1,200m, 29.i.1976, ex Cassinia vauvilliersii, J.S. Dugdale (NZAC); 2 9, Hokonui Hills, Bare Hill, 700m, 11.v.1984, emerged from Cassinia vauvilliersii in lab on 20.vii.1984, J.S. Dugdale (NZAC); OL: 1 ○, Key Summit, 2,600ft, Hollyford Valley, 12.i.1967, from Cassinia, A.K. Walker (NZAC).

Description. Male (Fig. 2)

Body length. 11.3-14.7 mm; width. 3.4-3.8 mm.

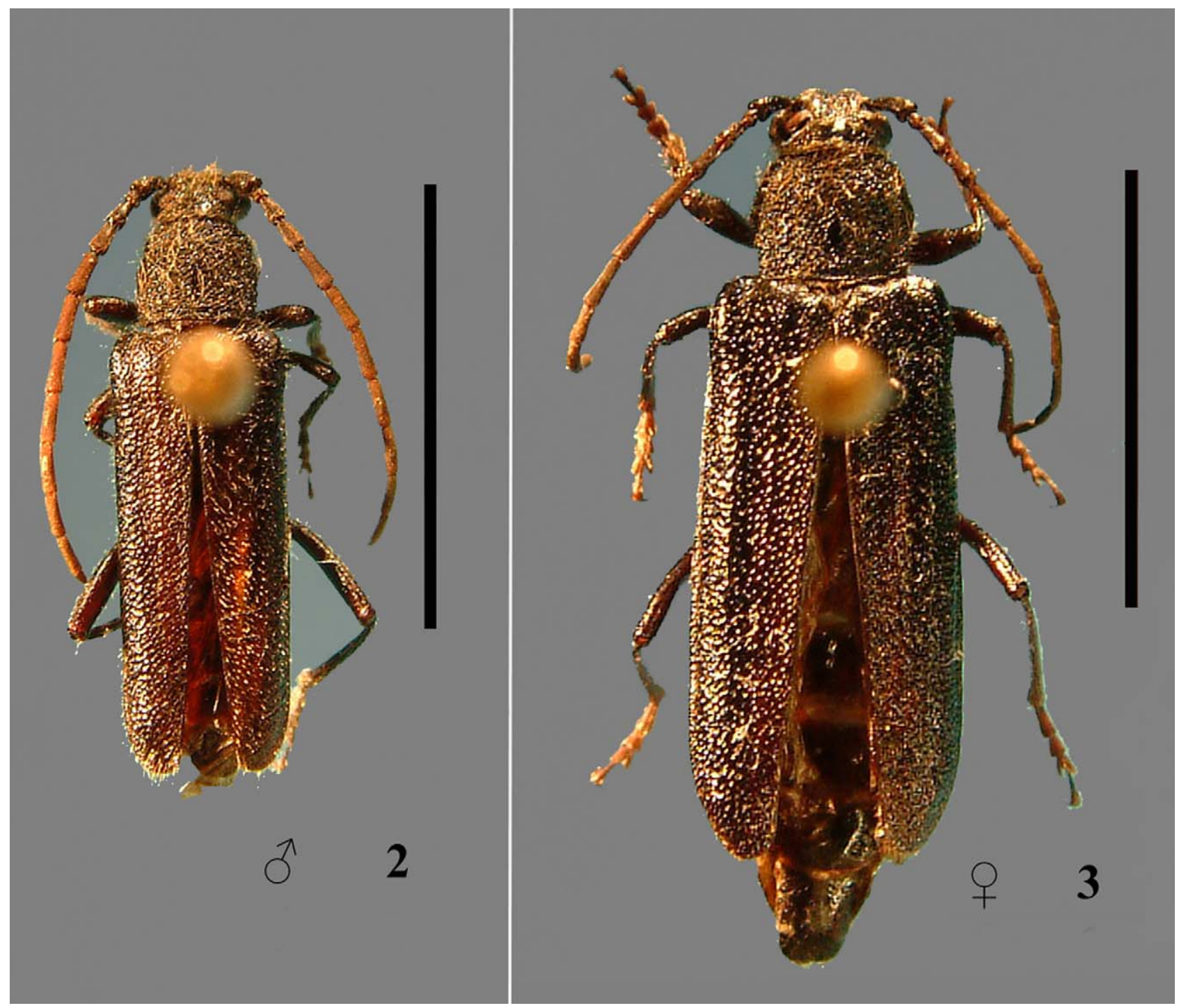

FIGURES 2-3. Dorsal view of Brounopsis nigrifacta, sp. nov. 2, male; 3, female. Scale bar = $10 \mathrm{~mm}$.

Colour. Antennae, palpi, labrum and legs reddish to blackish brown, tarsi and tibia maybe lighter; head, thorax 
and abdomen black or blackish brown; elytra black or blackish brown with a dark reddish brown epipleuron and a more or less vague dark reddish or pale longitudinal stripe near suture.

Head. Head with dense, coarse and deep punctures and long pale or yellowish hairs; head width $2.6-2.8 \times$ as long as distance between upper lobes of eyes; head width immediately below eyes 4.4-5.0 $\times$ as long as genal length. Antennae reaching beyond middle elytra; scape 1.2-1.3 $\times$ as long as segment 3 .

Thorax and abdomen. Prothorax width 1.1-1.2 $\times$ as long as length, each side with a rounded tubercle near middle. Pronotal disc with dense, coarse punctures, each bearing a long pale or yellowish hair; disc with 2 slightly raised tubercles before middle and 2 clearly depressed areas behind middle. Sterna with dense and irregular punctures and dense long pale or yellowish hairs. Elytra 3.8-4.0 $\times$ as long as prothorax; elytral disc with dense coarse punctures, each bearing a pale hair; most hairs in middle area $<2 \times$ as long as puncture diameter; apex rounded. Hind femur 1.07-1.11 $\times$ as long as hind tibia; hind tarsal segment $1<$ or as long as segments $2+3$. Abdomen with dense punctures, coarser on basal sternites and finer on apical sternites, and with dense long pale or yellowish hairs; surface with fine granular structure, giving a less shiny looking.

Female (Fig. 3)

Body length. 12.9-16.9 mm; width. 3.9-4.7 mm.

Antennae shorter, not reaching middle elytra; prothorax width $1.15-1.3 \times$ as long as length; elytra $4.2-4.4 \times$ as long as prothorax; abdomen shiny with less dense and finer punctures, and less dense and shorter hairs.

Biology. Known host is Cassinia vauvilliersii. Adults emerged in November to January.

Distribution. Southland and Otago Lakes of South Island.

Etymology. Named in reference to black head, pronotum and elytra.

Comments. The new species resembles $B$. hudsoni but differs in having elytra black and most hairs in the middle area of elytra $<2 \times$ as long as puncture diameter.

\section{Brounopsis hudsoni Blair}

(Figs 4-5)

B. hudsoni Blair, 1937: 267.

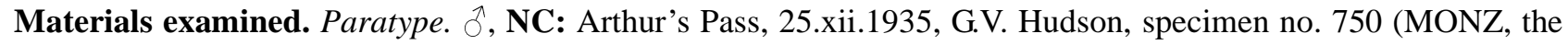
specimen bears a yellow circular cotype label; several segments of left antenna missing).

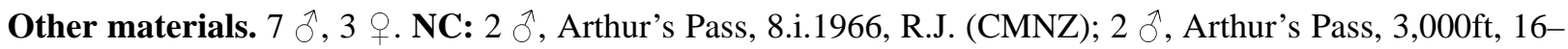
19.xii.1959, J. Townsend \& J.S. Dugdale (NZAC); 1 + , Arthur's Pass, 3,500ft, 12.xii.1922, J.G. Myers (NZAC); 1 + , Arthur's Pass, 6.i.1948, E. Fairburn (WMNZ); NN: 1 ภ, Lawrence, 1.iv.1912, R.C. O'Connor (NZAC); LOCALITY UNKNOWN: 2 ภ, 1 (MONZ).

Description. Male (Fig. 4).

Body length. 11.3-13.3 mm; width. 3.0-3.7 mm.

Colour. Antennae yellowish brown to blackish brown throughout, or yellowish brown with darker scape, segments 2 and 5-11; palpi yellowish to reddish brown; head and thorax black; legs yellowish to reddish brown; elytron pale to reddish brown with 2 dark reddish brown or blackish brown stripes: 1 at suture extending from base to basal $1 / 3-2 / 3$, and 1 on edge between disc and epipleuron extending from base to apical $1 / 4-1 / 3$ but usually not reaching apex.

Head. Head with dense, coarse and more or less irregular punctures and long yellowish brown hairs; head width 2.4-2.7 $\times$ as long as distance between upper lobes of eyes; head width immediately below eyes $4.5-5.0 \times$ as long as genal length. Antennae reaching far beyond middle elytra; antennal scape 1.14-1.28 $\times$ as long as segment 3. Thorax and abdomen. Prothorax width $1.10-1.14 \times$ as long as length; sides rounded or slightly produced near middle. Pronotal disc with dense, coarse and irregular punctures, each bearing a long golden hair; disc with 2 slightly raised tubercles before middle, and 2 depressed areas behind middle, denser and shorter hairs arising from these depressed areas. Sterna with dense and relatively fine punctures and long golden hairs. Elytra 3.53-4.03 $\times$ as long as prothorax; elytral disc with dense and round punctures, each bearing a yellowish brown hair, and most hairs in middle area $>2 \times$ as long as puncture diameter; apex rounded. Hind femur 1.11-1.17 $\times$ as long as tibia; hind tarsal segment $1<$ segments $2+3$. Abdomen shiny with relatively dense and fine punctures bearing fine and long and short golden hairs. 


\section{Female (Fig. 5).}

Body length. 13.8-15.2 mm; width. 3.7-4.2 mm.

Antennae slightly shorter but reaching beyond middle elytra; prothorax width $1.12-1.22 \times$ as long as length; elytra $4.02-4.47 \times$ as long as prothorax.

Biology. Hosts unknown. Adults emerged from December to January, and in April.

Distribution. North Canterbury and Nelson of South Island.

Comments. This species resembles B. gourlayi sp. nov. but differs in elytral apex rounded and dark stripes on elytra not reaching apex.

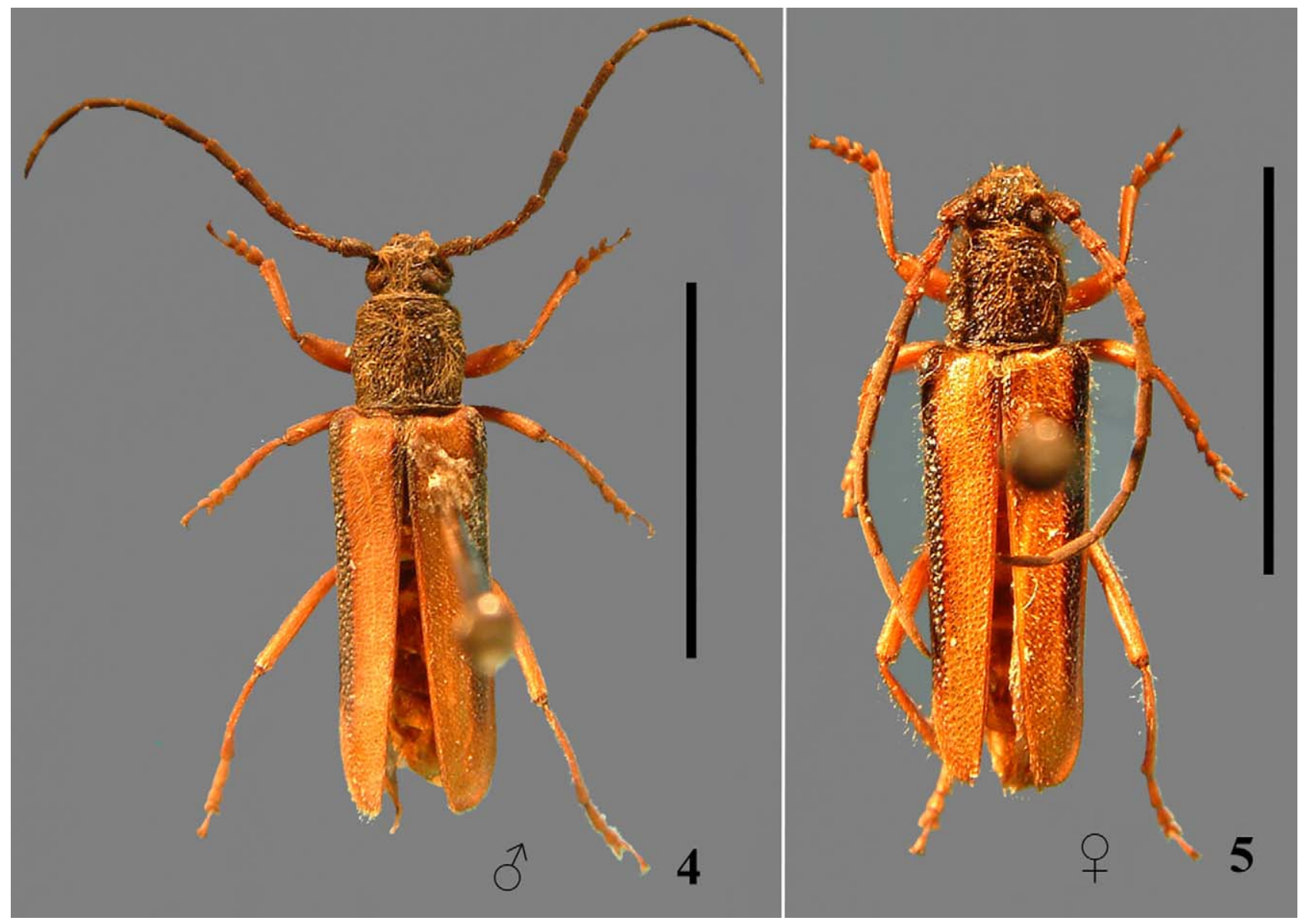

FIGURES 4-5. Dorsal view of Brounopsis hudsoni. 4, male; 5, female. Scale bar = $10 \mathrm{~mm}$.

\section{Brounopsis deitzi, sp. nov.}

(Figs 6-7)

Material examined. Holotype. Ô, SL: Takitimu Range, 1200 m, on Cassinia vauvilliersii, 29.i.1979, L.L. Deitz (NZAC, the specimen bears a red holotype label).

Paratypes. 2 , , SL: 1 + , Tapanui, Blue Mts., 970 m, emerged from Cassinia vauvilliersii on 8.xii.1985, plant material collected on 20.xi.1985, J.S. Dugdale (NZAC); 1 \%, MK: Mt. Cook Nat. Pk., on sand, 900 m, W.J. Sweney (MZAC).

Description. Male (Fig. 6).

Body length. $12.8 \mathrm{~mm}$; width. $3.4 \mathrm{~mm}$.

Colour. Antennae black almost throughout; palpi dark reddish brown with apical part of each segment lighter; head black; pronotum mostly black with the raised tubercle on disc near base and areas below lateral tubercles reddish brown; apical femur, apical tibia and tarsus black and remaining femur and tibia reddish brown; elytron pale with 2 dark reddish or blackish brown strips, both extending from base to apex: 1 narrow at suture and 1 wide on edge between disc and epipleuron. 
Head. Head with dense, coarse and more or less round punctures and long pale hairs; head width $2.74 \times$ as long as distance between upper lobes of eyes; head width immediately below eyes $5.57 \times$ as long as genal length. Antennae reaching far beyond middle elytra but not apex; antennal scape $1.26 \times$ as long as segment 3 .

Thorax and abdomen. Prothorax width $1.2 \times$ as long as length; each side of pronotum with a clearly defined and produced tubercle. Pronotal disc with dense, coarse and mostly round punctures, each bearing a long pale hair; disc with a raised, shiny and longitudinal tubercle between middle and base. Sterna with dense, fine and irregular punctures and pale or yellowish long hairs. Elytra $3.9 \times$ as long as prothorax; elytral disc with dense and round punctures, each bearing a pale or yellowish hair, and most hairs in middle area $<2 \times$ as long as puncture diameter; apex truncate. Hind femur $1.02 \times$ as long as hind tibia; hind tarsal segment $1>$ segments $2+3$. Abdomen with dense and irregular punctures, and with dense pale or yellowish hairs.

Female (Fig. 7).

Body length. 13.5-17.5 mm; width. 3.2-4.2 mm.

Antennae shorter, reaching or slightly beyond middle elytra; prothorax width $1.18-1.21 \times$ as long as length; elytra $>4 \times$ as long as prothorax; elytral apex more or less rounded; abdomen with less dense and finer punctures.

Biology. Known host is Cassinia vauvilliersii. Adults emerged in November to January.

Distribution. Southland and Mt Cook National Park of South Island.

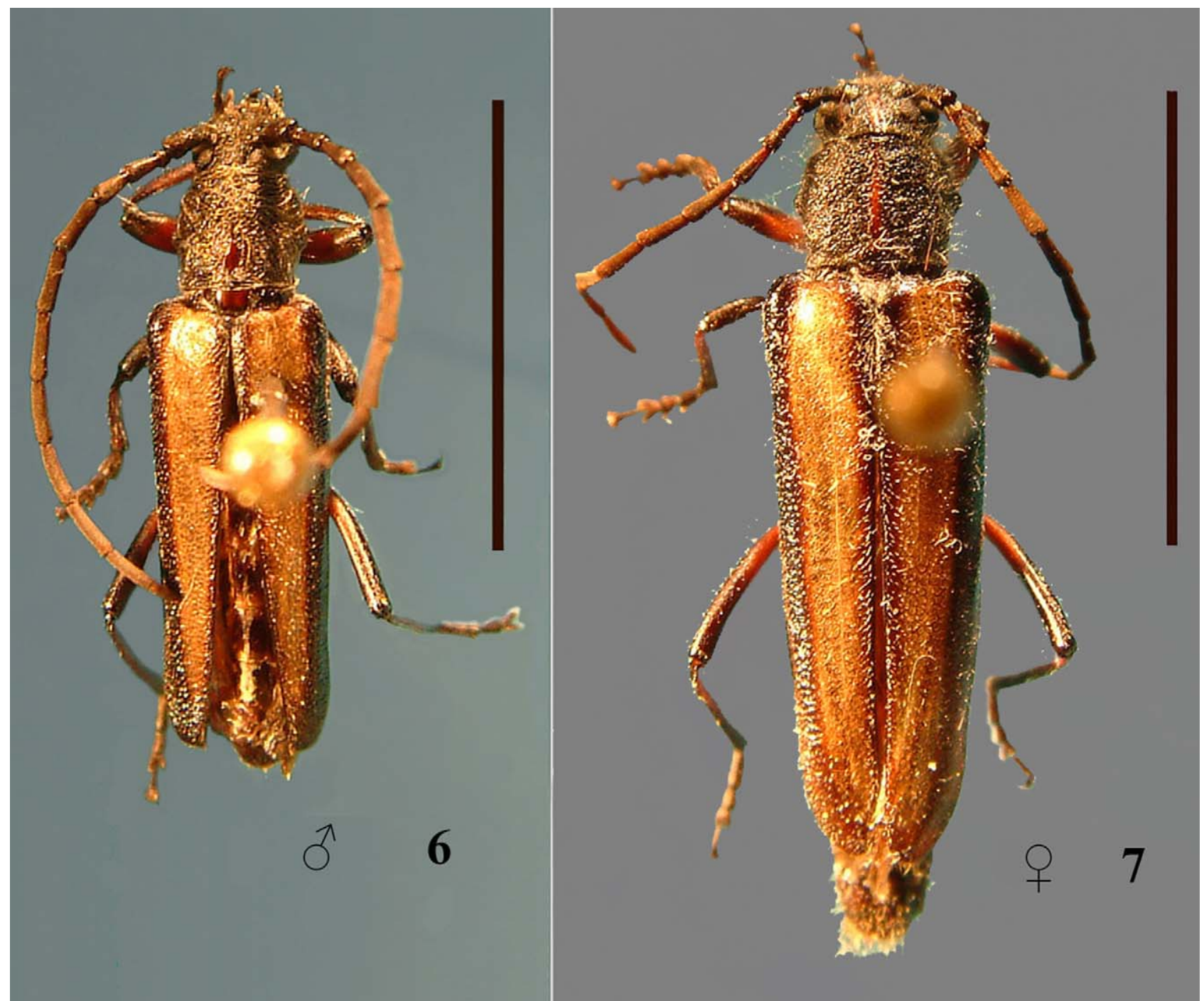

FIGURES 6-7. Dorsal view of Brounopsis deitzi, sp. nov. 6, male; 7, female. Scale bar = $10 \mathrm{~mm}$.

Etymology. Named in honour of the collector of the holotype, Dr. L. L. Deitz.

Comments. The new species resembles B. gourlayi sp. nov. but differs in having each side of pronotum with a clearly defined and produced tubercle and punctures on the middle area of elytral disc $<2 \times$ as long as puncture diameter. 
Brounopsis gourlayi, sp. nov.

(Figs 8-9)

Material examined. Holotype. Ô, MB: Awatere Valley, i.1961, reared from Cassinia leptophylla, E.S. Gourlay (NZAC, the specimen bears a red holotype label).

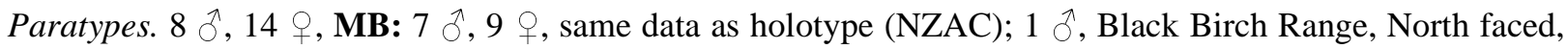
4300ft, emerged from Cassinia leptophylla, 21.x.1970 (NZAC); 1 q, Awatere Valley, emerged from Cassinia leptophylla, 18.x.1961, E.S. Gourlay (NZAC); 3 \%, Dashwood Pass, Cassinia leptophylla, E.S. Gourlay (NZAC); MK: 1 +, Murchison, 1000 m, Mt. Cook Nat. Pk., 8.v.1977, W.J. Sweney (NZAC).

Other material not designated as types. $3 \hat{\jmath}, 2$ क, MB: 1 ก, Waiau, 19.xi.1929, Wakefield Col. (CMNZ); 1 , , 1 , same data as holotype but abdomens in vials attached to the specimens (NZAC); CO: 1 \% , Waipori Stony Stream, 600 m, emerged from Cassinia on 28.xi.1979, plant material collected on 2.xi.1979, B. Barratt, abdomen in a vial attached to the specimen (NZAC); NN: 1 ڤึ, Maungatapu, Nelson, 18.i.1917 (NZAC).

Description. Male (Fig. 8).

Body length. 12.0-13.2 mm; width. 3.0-3.8 mm.

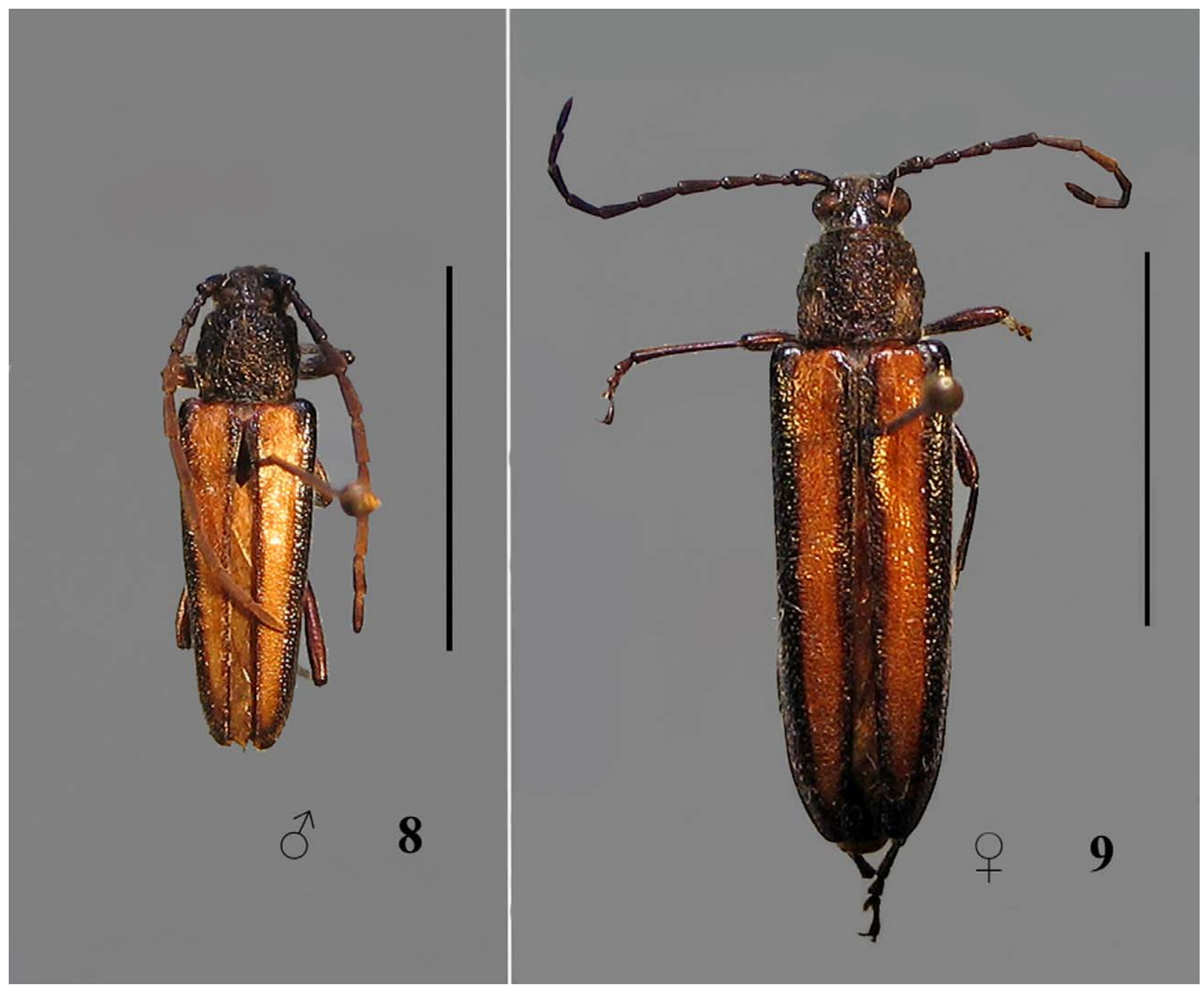

FIGURES 8-9. Dorsal view of Brounopsis gourlayi, sp. nov. 8, male; 9, female. Scale bar = 10 mm.

Colour. Antennal segments 1-5 black or blackish brown and remaining segments black, blackish brown or reddish brown; palpi dark reddish or yellowish brown; head black with reddish or yellowish brown labium and anteclypeus; pronotum black or blackish brown with areas near prosternum reddish brown; legs blackish or reddish brown; elytron pale with 2 black or blackish brown stripes: 1 narrow at suture and 1 wide on edge between disc and epipleuron, both extending from base to apex. 
Head. Head with dense and irregular punctures and long pale or yellowish hairs; head width $2.32-2.81 \times$ as long as distance between upper lobes of eyes; head width immediately below eyes $4.23-4.90 \times$ as long as genal length. Antennae reaching far beyond middle elytra; antennal scape $1.20-1.45 \times$ as long as segment 3 .

Thorax and abdomen. Prothorax width $1.09-1.13$ as long as length; sides rounded or slightly produced near middle; pronotal disc with dense, coarse and irregular punctures, each bearing a long pale or yellowish hair; disc with 2 slightly raised tubercles before middle, 2 slightly depressed areas behind middle, and denser and shorter hairs arising from these depressed areas. Sterna with dense, fine and irregular punctures and long pale or yellowish hairs. Elytra 3.40-3.60 $\times$ as long as prothorax; elytral disc with dense and round punctures, each bearing a pale hair and most hairs in middle area $>2 \times$ as long as puncture diameter; apex truncate. Hind femur $1.10-1.20 \times$ as long as tibia; hind tarsal segment $1>$ segments $2+3$. Abdomen with dense and fine punctures and pale hairs.

Female (Fig. 9).

Body length. 13.5-19.5 mm; width. 3.5-4.9 mm.

Antennae reaching or slightly beyond middle elytra; prothorax width $1.15-1.22 \times$ as long as length; elytra 4.01-4.31 $\times$ as long as prothorax.

Biology. Known host is Cassinia leptophylla (G.Forst.). Adults emerged in October to January, and in May.

Distribution. Nelson, Marlborough, Mt Cook National Park, and Central Otago of South Island.

Etymology. Named in honour of the collector of the holotype, Dr. E. S. Gourlay.

Comments. This new species resembles B. deitzi sp. nov. but differs in having each side of pronotum rounded or feebly tuberculate and most hairs from punctures on elytral disc $>2 \times$ as long as puncture diameter.

\section{Acknowledgements}

We would like to thank R. Leschen, T. Crosby and L. Clunie (NZAC), P. Sirvid and R. Palma (MONZ), S. Tengblad (WMNZ), J. Marris (LUNZ), and M. Walker (CMNZ) for making available the material included in this study; two anonymous referees and the Editor, L. Chamorro, for constructive comments; and New Zealand Lottery Science Grant (SR45340), Massey University Research Fund, and National Natural Science Foundation of China (No. 31260432) for financial support.

\section{References}

Bense, U. (1995) Longhorn Beetles: Illustrated Key to the Cerambycidae and Vesperidae of Europe, Margraf, Germany, 512 pp.

Blair, K.G. (1937) Synonymy of the cerambycidae of New Zealand (Col.). The Entomologist's Monthly Magazine, 73, $261-268$.

Crosby, T.K., Dugdale, J.S. \& Watt, J.C. (1998) Area codes for recording specimen localities in the New Zealand subregion. New Zealand Journal of Zoology, 25, 175-183. http://dx.doi.org/10.1080/03014223.1998.9518148

Lawrence, J. F. \& Britton, E. B. (1991) Coleoptera. In The Insects of Australia: A Textbook for Students and Research Workers. (ed. CSIRO), Melbourne University Press, Melbourne, pp 543-683.

Leschen, R.A.B., Lawrence, J.F., Kuschel, G., Thornpe, S. \& Wang, Q. (2003) Coleoptera genera of New Zealand. New Zealand Entomologist, 26, 15-28. http://dx.doi.org/10.1080/00779962.2003.9722105

Lu, W. \& Wang, Q. (2005a) Systematics of the New Zealand longicorn beetle genus Oemona Newman with discussion of the taxonomic position of the Australian species, O. simplex White (Coleoptera: Cerambycidae: Cerambycinae). Zootaxa, $971,1-31$.

Lu, W. \& Wang, Q. (2005b) Systematics of the longicorn beetle genus Ophryops (Coleoptera: Cerambycidae). Invertebrate Systematics, 19, 169-188. http://dx.doi.org/10.1071/IS04026

Orchard, A.E. (2004) A revision of Cassinia (Asteraceae: Gnaphalieae) in Australia. 1. Introduction and generic and infrageneric considerations. Australian Systematic Botany, 17, 469-481. http://dx.doi.org/10.1071/SB04025

Wang, Q. (1998) The phoracanthine beetles (Coleoptera: Cerambycidae): Taxonomic overview and generic relationships. Invertebrate Taxonomy, 12, 667-684. http://dx.doi.org/10.1071/IT96040

Wang, Q. \& Lu, W. (2004) A systematic revision of New Zealand longicorn beetle genus Drototelus Broun (Coleoptera: Cerambycidae). Invertebrate Systematics, 18, 649-659. http://dx.doi.org/10.1071/IS03040 